\title{
Does Cystatin C have a role as metabolic surrogate in peritoneal dialysis beyond its association with residual renal function?
}

Teria a Cistatina C um papel como substituto metabólico na diálise peritoneal além de sua associação com a função renal residual?

\section{Authors}

Carla Leal Moreira ${ }^{1}$ iD

Liliana Cunha ${ }^{1}$ id

Sofia Correia ${ }^{1}$ (i)

Filipa Silva ${ }^{10}$

Ana Castro ${ }^{1}$ (i)

Joana Tavares ${ }^{1}$ id

Maria João Carvalho' ${ }^{1}$ (i)

José Carlos Oliveira ${ }^{2}$

Olívia Santos ${ }^{1}$ D

António Cabrita' ${ }^{10}$

Anabela Rodrigues ${ }^{1}$ (D)

${ }^{1}$ Centro Hospitalar do Porto, Hospital de Santo António, Departamente de Nefrologia, Porto, Portugal.

${ }^{2}$ Centro Hospitalar do Porto, Hospital de Santo António, Departamento de Patologia,Porto, Portugal.

Submitted on: 01/09/2019. Approved on: 06/06/2019.

\section{Correspondence to:}

Carla Leal Moreira

E-mail: moreira.I.s.carla@gmail.com

DOI: 10.1590/2175-8239-JBN-2019-0007

\section{Abstract}

Introduction: It has been suggested that cystatin $\mathrm{C}$ levels are modified by obesity and inflammation. Furthermore, cystatin $\mathrm{C}$ has been associated with cardiovascular events and mortality outcomes. Aim: To study the association of cystatin $\mathrm{C}$ with the metabolic profile and cardiovascular disease of peritoneal dialysis patients. Methods: Data collected included clinical, laboratorial, and multifrequency bioimpedance assessment of 52 stable peritoneal dialysis patients. Minimal residual renal function was defined as > $2 \mathrm{~mL} / \mathrm{min} / 1.73 \mathrm{~m}^{2}$. Results: Serum cystatin $\mathrm{C}$ was not significantly associated with peritoneal or urinary cystatin $\mathrm{C}$ excretion. Negative correlation of cystatin $C$ with normalized protein catabolic rate (rho $-0.33, p=0.02$ ) and a trend towards positive correlation with relative body fat (rho 0.27, $p=0.05$ ) were not independent from residual renal function. Cystatin $\mathrm{C}$ was not significantly associated with cardiovascular disease $(p=0.28)$, nor with glycated hemoglobin $(p=0.19)$ or c-reactive protein $(p=0.56)$. In the multivariate model, both age and diabetes were the strongest predictors of cardiovascular disease (odds ratio 1.09, $p$ $=0.029$ and odds ratio $29.95, p=0.016$, respectively), while relative body fat was negatively associated with cardiovascular disease $(p=0.038)$; neither cystatin $\mathrm{C}$ $(p=0.096)$ nor minimal residual renal function $(p=0.756)$ reached a significant association with cardiovascular disease. Conclusions: In this group of peritoneal dialysis patients, cystatin C did not correlate with the metabolic or inflammatory status, nor cardiovascular disease, after adjustment for residual renal function.

Keywords: Cystatin C; Cardiovascular Diseases; Peritoneal Dialysis.

\section{Resumo}

Introdução: Tem sido sugerido que os níveis de cistatina C são modificados pela obesidade e inflamação. Além disso, a cistatina $\mathrm{C}$ tem sido associada a eventos cardiovasculares e desfechos de mortalidade. Objetivo: Estudar a associação da cistatina $\mathrm{C}$ com o perfil metabólico e doença cardiovascular de pacientes em diálise peritoneal. Métodos: Os dados coletados incluíram avaliação clínica, laboratorial e de bioimpedância múltipla de 52 pacientes estáveis em diálise peritoneal. A função renal residual mínima foi definida como $>2 \mathrm{~mL} / \mathrm{min} / 1,73 \mathrm{~m}^{2}$. Resultados: A cistatina $C$ sérica não esteve significativamente associada à excreção peritoneal ou urinária. A correlação negativa da cistatina $\mathrm{C}$ com a taxa catabólica protéica normalizada (rho $-0,33, p=0,02$ ) e uma tendência de correlação positiva com a gordura corporal relativa (rho $0,27, p=$ $0,05)$ não foram independentes da função renal residual. A cistatina $C$ não se associou significativamente à doença cardiovascular $(p=0,28)$, nem com hemoglobina glicada $(p=0,19)$ ou proteína $C$ reativa $(p=0,56)$. No modelo multivariado, idade e diabetes foram os mais fortes preditores de doença cardiovascular (razões de probabilidade 1,09, $p=0,029$ e 29,95, $p=0,016$, respectivamente) enquanto a gordura corporal relativa se associou negativamente à doença cardiovascular $(p=0,038)$. A cistatina $\mathrm{C}$ não se associou significativamente com doença cardiovascular $(p=0,096)$, tampouco a função residual mínima $(p=$ 0,756). Conclusão: Neste grupo de pacientes em diálise peritoneal, a cistatina $C$ não se correlacionou com o estado metabólico ou inflamatório, nem com doença cardiovascular, após ajuste para função renal residual.

Palavras-chave: Cistatina C; Doenças Cardiovasculares; Diálise Peritoneal. 


\section{INTRODUCTION}

Cystatin $\mathrm{C}$ (CysC) has been proposed to be strongly associated with cardiovascular events and mortality outcomes. Furthermore, some authors report that $\mathrm{CysC}$-based estimated glomerular filtration rate (eGFR) is associated with all-cause mortality and cardiovascular events independent of both measured or creatinine-based eGFR ${ }^{1-3}$.

Cystatin $\mathrm{C}$ is a low molecular weight $(13.3 \mathrm{kDa})$ protein that is freely filtered, almost totally reabsorbed and metabolized in proximal tubule of the nephron ${ }^{4}$. It is also known for its constant production (by nucleated cells), except in the cases of steroid users, obesity, inflammation, and thyroid malfunction. Additionally, it has been found to be poorly influenced by body mass composition, diet, gender and ethnic group, supporting the use of $\mathrm{Cys} C$-based equations for GFR estimation in pre-dialysis patients ${ }^{5-7}$.

Moreover, serum CysC accuracy in estimating residual renal function has been studied in peritoneal dialysis (PD) patients ${ }^{8-10}$ and its potential role beyond GFR prediction has been also investigated. CysC has been suggested to be an independent predictor of mortality, cardiovascular events, and end-stage renal disease (ESRD $)^{11,12}$. In kidney transplant recipients, CysC was found to be an independent predictor of cardiovascular events, mortality, and kidney failure ${ }^{13}$. Furthermore, in patients with negligible GFR (hemodialysis and peritoneal dialysis patients) CysC maintained its predictive power for adverse outcomes ${ }^{14}$.

We hypothesized that CysC has a role beyond GFR estimation. Therefore, we conducted a cross-sectional study to evaluate $\mathrm{Cys} C$ ability to predict metabolic and major cardiovascular disease (CVD) in peritoneal dialysis $(\mathrm{PD})$ patients.

\section{Methods}

We performed a cross-sectional study enrolling 52 patients followed in our outpatient PD clinic at Centro Hospitalar do Porto (CHP) from October 2016 until January 2017. Patients were included if clinically stable and on PD therapy for at least 3 months, and excluded if acutely ill. The clinical and laboratorial data were collected as part of the national quality control and approved by national data protection committee. A single assessment of serum, urinary, and peritoneal effluent CysC levels was determined by an automated particleenhanced nephelometric immunoassay (Dimension Vista 500, Siemens Healthcare). Other laboratory measurements were performed in the laboratories of the
CHP using standardized and automated methods. Lean tissue mass (LTM), fat mass, body cell mass (BCM), and relative overhydration $(\mathrm{rel} . \mathrm{OH})$ were assessed by the multifrequency bioimpedance method using the Body Composition Monitor (BCM, Fresenius Medical Care, Bad Homburg, Germany). The bioimpedance method applied was validated by isotope dilution methods ${ }^{15}$, by accepted reference body composition methods ${ }^{16,17}$, and by extensive clinical assessment of the hydration state ${ }^{18}$. Body composition assessment was obtained with full abdomen. The patient was weighed after draining out peritoneal effluent and thereafter 2 liters of peritoneal solution were instilled. All BCM measurements were performed by a trained nurse with the patient in supine position on a non-conductive bed, in resting conditions. Two non-recyclable electrode strips were placed on the dorsal surface of the wrist and foot on one side of the body and connected to the BCM device.

Patients' past medical history, including major cardiovascular events, medication, PD modality, dialysis adequacy, daily exchange volume, and ultrafiltration were collected. Self-reported major cardiovascular disease at baseline included prior myocardial infarction, coronary artery revascularization, stroke, or carotid arterial revascularization. Adequacy of dialysis was calculated from 24-hour urine and dialysate collection. Weekly $\mathrm{Kt} / \mathrm{V}$ was determined using standard methods ${ }^{19}$. Residual renal function (RRF) was assessed simultaneously with Cys $C$ evaluation, using the average clearance of urea and creatinine (CrUCL) in 24-h urine collection, as described elsewhere ${ }^{20}$. Patients were considered to have minimal RRF if $\mathrm{CrUCL}>2 \mathrm{~mL} / \mathrm{min} / 1.73 \mathrm{~m}^{2}$. A panel of metabolic biomarkers including HOMA-IR (homeostasis model assessment insulin resistance index), leptin, lipid profile, and insulin was obtained on the same day of peritoneal equilibration test. Dietary protein intake was estimated from protein catabolic rate normalized to actual body weight (nPCR) using the PD Adequest software (Baxter Healthcare Corporation, Deerfield, IL). All patients were treated with low-glucose degradation product solutions; $3.86 \%$ glucose exchanges were not routinely used. Icodextrin was used in $27(51.9 \%)$ patients.

The primary outcome was the correlation of CysC with cardiovascular disease. Secondary outcomes were $\mathrm{Cys} C$ correlation with the metabolic panel and bioimpedance measurements. The results are reported as the mean \pm standard deviation or median and interquartile range (IQR) according to normality distribution. The association between 
CysC and other variables was estimated using Spearman's rank correlation for continuous variables and Wilcoxon rank-sum test for categorical data. Chi-square test was applied to categorical variables. We assessed the association of $\mathrm{Cys} C$ level with CVD and metabolic parameters using adjusted logistic and linear regression, respectively. RRF was the only confounding variable included in the linear regression model of $\mathrm{CysC}$ correlation with metabolic parameters. Clinically significant and statistically significant variables were included in the adjusted model of CVD prediction. Measures of association are reported as odds ratio (OR) and $95 \%$ confidence intervals $(\mathrm{CI})$. A $p$ value $<0.05$ was considered statistically significant. Statistical analysis was performed in Stata, version 14.0 (StataCorp LP ${ }^{\circledR}$ ).

\section{RESULTS}

Fifty-two patients were eligible for this study, of which $52 \%(\mathrm{n}=27)$ were male patients, mean age was $51.5 \pm 13.8$ years. Time on PD was 21.6 (13.1 -50.3) months and most patients received continuous ambulatory PD $(\mathrm{n}=30,58 \%)$. The prevalence of diabetes and hypertension was $11.5 \%(\mathrm{n}=6)$ and $94 \%$ $(\mathrm{n}=49)$, respectively; 50\% $(\mathrm{n}=26)$ had medicated dyslipidemia. Fifteen (19\%) patients reported current or past smoking habits. Twelve patients reported previous history of cardiovascular disease, 10 patients $(19 \%)$ were previously diagnosed with ischemic heart disease (IHD), and four patients $(8 \%)$ with a prior stroke. The baseline characteristics of this cohort are listed on Table 1.

The median serum level of CysC was 5.9 (4.7 6.9) $\mathrm{mg} / \mathrm{L}$, with the median level of serum creatinine being 8.6 (6.8 -12.2) $\mathrm{mg} / \mathrm{dL}$. Twelve patients $(23.1 \%)$ presented a daily urine output $<200 \mathrm{~mL}$. Median RRF was $4.0(2.4-8.3) \mathrm{mL} / \mathrm{min} / 1.73 \mathrm{~m}^{2}$. All participants had adequate dialysis clearances according to the weekly $\mathrm{Kt} / \mathrm{V}$ and creatinine clearance (CrCL). The median weekly $\mathrm{Kt} / \mathrm{V}$ was 2.0 (1.8 - 2.4). Complementary laboratorial data on mineral bone disease and metabolic parameters are listed on Table 1.

The body composition was analyzed providing additional data regarding hydration and nutritional status (Table 2).

Patients with IHD (6.5 vs $5.7 \mathrm{mg} / \mathrm{L}, p=0.44)$ and cerebrovascular disease $(6.2$ vs $5.7 \mathrm{mg} / \mathrm{L}, p=0.41)$ had a trend for higher levels $\mathrm{CysC}$, without reaching statistical significance, Table 3 . When the composite

\begin{tabular}{lc} 
TABLE 1 & $\begin{array}{c}\text { BASELINE CHARACTERISTICS OF PREVALENT } \\
\text { PERITONEAL DIALYSIS PATIENTS }\end{array}$ \\
\hline Variables & $\mathrm{N}$ \\
\hline Number of patients & 52 \\
Age (years), mean (SD) & $51.5 \pm 13.8$ \\
Gender (males) & $27(52 \%)$ \\
Hypertension & $49(94 \%)$ \\
Diabetes Mellitus & $6(11.5 \%)$ \\
Dyslipidemia & $26(50 \%)$ \\
Smoking status & \\
Non-smoker & $37(71 \%)$ \\
Previous smoker & $9(17 \%)$ \\
Current smoker & $6(1 \%)$ \\
Chronic kidney disease etiology & \\
Diabetic nephropathy & $3(6 \%)$ \\
ADPKD & $3(6 \%)$ \\
Chronic GN & $30(58 \%)$ \\
Nephrosclerosis & $1(2 \%)$ \\
Other & $15(29 \%)$ \\
Ischemic heart disease (\%) & $10(19 \%)$ \\
Cerebrovascular disease (\%) & $4(8 \%)$ \\
Charlson Comorbidities Index, median (IQR) & $3(2,4)$
\end{tabular}

Total time on Renal Replacement

Therapy (months)

Time on PD duration (months)

PD modality

APD

CAPD

$33.1(16.0,77.5)$

$21.6(13.1,50.3)$

Weekly Kt/N

Weekly CrCL (L/1.73m²)

Serum CysC (mg/L)

Serum Creatinine $(\mathrm{mg} / \mathrm{dL})$

$\mathrm{CrUCL}\left(\mathrm{mL} / \mathrm{min} / 1.73 \mathrm{~m}^{2}\right)$

Hemoglobin (g/dL)

Metabolic status

$\mathrm{HbA} 1 \mathrm{C}(\%)$

Glucose (mg/dL)

Insulin $(\mathrm{UI} / \mathrm{mL})$

HOMA-IR

Leptin $(\mathrm{ng} / \mathrm{mL})$

Total Cholesterol (mg/dL)

LDL-cholesterol (mg/dL)

$\mathrm{HDL}$ - cholesterol (mg/dL)

Triglyceride $(\mathrm{mg} / \mathrm{dL})$

$\mathrm{nPCR}(\mathrm{g} / \mathrm{Kg})$

Albumin $(\mathrm{g} / \mathrm{dL})$

b2-M (mg/L)

C-Reactive Protein (mg/L)

Mineral bone disease

Intact parathyroid hormone (pg/mL)

Calcium (mmol/L)

$22(42 \%)$

$30(58 \%)$

$2.0(1.8,2.4)$

$72.5(56.7,95.1)$

$5.9(4.7,6.9)$

$8.6(6.8,12.2)$

$4.0(2.4,8.3)$

$10.90(9.75,11.60)$

$5.5(5.3,5.9)$

$90(81,105.5)$

$11.2(7.6,17)$

$2(2,4)$

$48.4(15.4,84.9)$

$173(151,196)$

$96.5(73.5,121)$

$41(33.5,56)$

$161(98,209)$

$1.0(0.9,1.3)$

$3.9(3.8,4.2)$

$23.5(17.5,33.1)$

$3.2(0.7,9.3)$

$521.4(303.5,665.5)$

$2.2(2.0 ; 2.3)$

Phosphate ( $\mathrm{mmol} / \mathrm{L})$

$1.5(1.3,1.8)$

Data presented as mean $\pm \mathrm{SD}$, median (interquartile range), or percent frequency, as appropriate. ADPKD: autosomal dominant polycystic kidney disease; GN glomerulonephritis; PD: peritoneal dialysis; APD: automatic peritoneal dialysis; CAPD: continuous ambulatory peritoneal dialysis; $\mathrm{CrCL}$ : creatinine clearance; CysC: cystatin C; CrUCL: clearance of urea and creatinine in 24-h urine collection; $\mathrm{HbA1c}$ : glycated hemoglobin; LDL: low density lipoprotein; HDL: high density lipoprotein; nPCR: normalized protein catabolic rate; $\beta$ 2-M: beta-2-microglobulin. 


\begin{tabular}{lc} 
TABLE 2 & BIOIMPEDANCE ASSESSMENT \\
\hline Factors & Value \\
\hline Weight (kg) & $71.8(62.8,82.2)$ \\
Relative OH (\%) & $5.8(0.4,11.8)$ \\
ECW (L) & $17.2(14.2,18.9)$ \\
ICW (L) & $18.9(15,21.5)$ \\
BMI (kg/m²) & $25.4(23,29.1)$ \\
LTM (kg) & $36.9(29.6,46.4)$ \\
Relative LTM (\%) & $51.9(41.7,60)$ \\
Fat (kg) & $23.5(17,32.3)$ \\
Relative Fat (\%) & $33.2(28.1,41.6)$ \\
Body Cell Mass (kg) & $19.8(15.6,26.3)$ \\
\hline Data presented as median (interquartile range). OH: overhydration. \\
ECW: extracellular weight; ICW: intracellular weight; BMI: body mass \\
index. LTM: lean total mass.
\end{tabular}

\begin{tabular}{|c|c|c|c|}
\hline TABLE 3 & \multicolumn{3}{|c|}{$\begin{array}{l}\text { CYSC LEVELS ACCORDING TO CARDIOVASCULAR } \\
\text { RISK FACTORS AND MAJOR CARDIOVASCULAR } \\
\text { DISEASE }\end{array}$} \\
\hline Factors & & $\begin{array}{c}\text { Median } \\
\text { CysC (mg/L) }\end{array}$ & $p$-value ${ }^{a}$ \\
\hline \multicolumn{2}{|c|}{ Gender (male/female) } & 6.1 vs 5.6 & 0.77 \\
\hline \multicolumn{2}{|c|}{ Hypertension $(\mathrm{Y} / \mathrm{N})^{*}$} & 5.8 vs 6.4 & 0.98 \\
\hline \multicolumn{2}{|c|}{ Diabetes Mellitus $(\mathrm{Y} / \mathrm{N})^{*}$} & 5.2 vs 5.9 & 0.38 \\
\hline \multicolumn{2}{|c|}{$\begin{array}{l}\text { Previous or current smoker } \\
\text { status }(\mathrm{Y} / \mathrm{N})^{*}\end{array}$} & 6.6 vs 5.6 & 0.10 \\
\hline \multicolumn{2}{|c|}{ Dyslipidemia $(\mathrm{Y} / \mathrm{N})^{*}$} & 5.7 vs 6.2 & 0.22 \\
\hline \multicolumn{2}{|c|}{ Ischemic heart disease $(\mathrm{Y} / \mathrm{N})^{*}$} & 6.5 vs 5.7 & 0.44 \\
\hline \multicolumn{2}{|c|}{ Cerebrovascular disease $(\mathrm{Y} / \mathrm{N})^{*}$} & 6.2 vs 5.7 & 0.41 \\
\hline
\end{tabular}

end-point of CVD was considered, serum CysC levels difference remained statistically non-significant $(6.5$ vs. $5.6 \mathrm{mg} / \mathrm{L}, p=0.28$ ).

Patients receiving automatic PD correlated positively with $\mathrm{CysC}$ (rho: 2.82, $p=0.005$ ), PD duration (rho $0.36, p=0.007$ ) and weekly peritoneal CrCL (rho: $0.43, p=0.002$ ), but inversely with weekly renal CrCL (rho: $-0.70, p<0.0001$ ), consistent with its correlation with RRF. CysC levels did not correlate significantly with the lipid profile, HOMA-IR score, or glycated hemoglobin, but correlated negatively with nPCR (rho: $-0.33, p=0.02$ ) and hemoglobin (rho: $-0.29, p=0.03$ ), Table 4 .

Regarding the bioimpedance evaluation, CysC correlated negatively with the relative total lean mass (rho: $-0.29, p=0.047$ ) and positively with the relative fat (rho: $0.27, p=0.05$ ), Table 5 .

In the linear regression model adjusted for RRF, CysC no longer correlated with lean mass, fat body composition, or nPCR. In the multivariate model

\begin{tabular}{|c|c|c|c|}
\hline TABLE 4 & \multicolumn{3}{|c|}{$\begin{array}{l}\text { CORRELATION ANALYSIS OF METABOLIC AND } \\
\text { INFLAMMATORY VARIABLES ASSOCIATED WITH } \\
\text { SERUM CYSC LEVEL }\end{array}$} \\
\hline \multicolumn{2}{|c|}{ Variables } & $\begin{array}{c}\text { Correlation } \\
\text { coefficient }\end{array}$ & $p$-value* \\
\hline \multicolumn{2}{|l|}{ Age } & -0.25 & 0.08 \\
\hline \multicolumn{2}{|l|}{$\begin{array}{l}\text { Charlson } \\
\text { Index }\end{array}$} & -0.19 & 0.16 \\
\hline \multicolumn{2}{|c|}{ PD modality } & 2.82 & 0.005 \\
\hline \multicolumn{2}{|c|}{ PD duration } & 0.36 & 0.007 \\
\hline \multicolumn{2}{|c|}{$\begin{array}{l}\text { Creatinine dialysate-to- } \\
\text { plasma ratio }\end{array}$} & -0.02 & 0.88 \\
\hline \multicolumn{2}{|c|}{ Weekly renal CrCL } & -0.70 & $<0.0001$ \\
\hline \multicolumn{2}{|c|}{ Weekly peritoneal $\mathrm{CrCL}$} & 0.43 & 0.002 \\
\hline \multicolumn{2}{|c|}{ Protein loss } & 0.11 & 0.42 \\
\hline \multicolumn{2}{|c|}{ Urinary CysC excretion } & 0.08 & 0.62 \\
\hline \multicolumn{2}{|c|}{ Peritoneal CysC excretion } & -0.03 & 0.83 \\
\hline \multicolumn{2}{|l|}{ Insulin } & -0.18 & 0.27 \\
\hline \multicolumn{2}{|l|}{ Leptin } & 0.12 & 0.48 \\
\hline \multicolumn{2}{|c|}{ HOMA-IR score } & -0.16 & 0.33 \\
\hline \multicolumn{2}{|c|}{ Total cholesterol } & 0.19 & 0.25 \\
\hline \multicolumn{2}{|c|}{ HDL-cholesterol } & -0.14 & 0.36 \\
\hline \multicolumn{2}{|l|}{ Albumin } & 0.14 & 0.34 \\
\hline \multicolumn{2}{|l|}{$\mathrm{HbA} 1 \mathrm{c}$} & -0.21 & 0.19 \\
\hline \multicolumn{2}{|l|}{$\mathrm{nPCR}$} & -0.33 & 0.02 \\
\hline \multicolumn{2}{|c|}{ C-Reactive Protein } & 0.08 & 0.56 \\
\hline \multicolumn{2}{|l|}{ Ferritin } & 0.09 & 0.51 \\
\hline \multicolumn{2}{|c|}{ Hemoglobin } & -0.29 & 0.03 \\
\hline
\end{tabular}

PD: peritoneal dialysis; $\mathrm{CrCL}$ : creatinine clearance; CysC: cystatin C; HOMA-IR: homeostasis model assessment insulin resistance index; HDL: high density lipoprotein; HbA1c: glycated hemoglobin; nPCR: normalized protein catabolic rate. ${ }^{*} A p$ value $<0.05$ was considered statistically significant.

\begin{tabular}{lcc} 
TABLE 5 & \multicolumn{3}{l}{$\begin{array}{l}\text { CORRELATION ANALYSIS OF BODY COMPOSITION } \\
\text { MONITORING VARIABLES WITH SERUM CYSC } \\
\text { LEVEL }\end{array}$} \\
\hline Variables & $\begin{array}{c}\text { Correlation } \\
\text { coefficient }\end{array}$ & p-value* \\
\hline Total weight $(\mathrm{kg})$ & 0.06 & 0.64 \\
Relative OH (\%) & 0.07 & 0.63 \\
Non-hydrated weight (kg) & 0.06 & 0.70 \\
ECW (L) & -0.06 & 0.67 \\
ICW (L) & -0.20 & 0.16 \\
BMI (kg/m ${ }^{2}$ ) & 0.21 & 0.14 \\
LTM (kg) & -0.22 & 0.12 \\
Relative LTM (\%) & -0.29 & 0.047 \\
Total fat (kg) & 0.22 & 0.13 \\
Relative fat (\%) & 0.27 & 0.05 \\
Body cell mass (kg) & -0.21 & 0.13 \\
\hline
\end{tabular}

OH: overhydration; ECW: extracellular weight; ICW: intracellular weight; BMI: body mass index; LTM: lean total mass. ${ }^{*} A$ $p$ value $<0.05$ was considered statistically significant. 
adjusted for minimal RRF, CysC, age, and diabetes, both age and diabetes were the strongest predictors for CVD (OR: 1.09, 95\% CI: 1.01-1.17, $p=0.029$ and OR: 29.95, 95\%CI: 1.87-479.98, $p=0.016$, respectively), with relative fat percentage associated negatively with CVD (OR: 0.91, 95\%CI: 1.01$1.17, p=0.038)$; CysC did not reach a statistically significant positive association with CVD (OR: 2.65, 95\%CI: 0.84-8.38, $p=0.096$ ), neither did minimal RRF $(p=0.756)$, Table 6 .

\section{Discussion}

To the best of our knowledge, this is the first study to address $\mathrm{Cys} C$ correlation with an extensive panel of metabolic biomarkers, bioimpedance metrics, and cardiovascular disease in PD patients.

Cardiovascular disease is the major cause of death in patients with chronic kidney disease, both in pre-dialysis patients and in end-stage renal disease. Moreover, incident PD patients have been shown to have an increased risk of cardiovascular mortality after the first year ${ }^{21}$. Authors have searched for serum biomarkers able to predict CVD and CVD mortality.

CysC has been suggested to be correlated with CVD in patients with normal renal function ${ }^{5}$. CysC independent correlation with CVD was hypothesized in a study where eGFR based on either creatinine or CysC was influenced by traditional cardiovascular risk factors even after adjusting for measured GFR ${ }^{1}$. Tangri et al. findings suggested that $\mathrm{CysC}$ was associated with kidney failure, CVD death, and all-cause mortality. In fact, adjustment for GFR strengthened the association of $\mathrm{Cys} C$ with mortality outcomes in pre-dialysis patients ${ }^{11}$.

Whether CysC represents a marker or has an active role in atherosclerosis process and its pathways remains to be clarified. CysC inhibitory activity is vital for the regulation of normal physiological processes

\begin{tabular}{|c|c|c|c|}
\hline \multirow[t]{2}{*}{ TABELA 6} & \multicolumn{3}{|c|}{$\begin{array}{l}\text { MULTIVARIATE ANALYSIS: ADJUSTED MODEL OF } \\
\text { PREDICTORS FOR CARDIOVASCULAR DISEASE }\end{array}$} \\
\hline & OR & $95 \% \mathrm{Cl}$ & $p$ value* \\
\hline Serum Cys & 2.65 & 0.84-8.37 & 0.096 \\
\hline RRF & 0.65 & $0.04-9.93$ & 0.756 \\
\hline Relative fat & 0.91 & 0.83-0.99 & 0.038 \\
\hline Diabetes & 29.95 & $1.87-479.98$ & 0.016 \\
\hline Age & 1.09 & $1.01-1.17$ & 0.029 \\
\hline
\end{tabular}

CysC: cystatin C; OR: odds ratio; $\mathrm{Cl}$ : confidence intervals; RRF: residual renal function. ${ }^{*} A p$ value $<0.05$ was considered statistically significant. by limiting the potentially highly destructive activity of its target proteases, including cysteine cathepsins. Naour et al. found a significant increase in CysC mRNA expression in omental and subcutaneous adipose tissue and three-fold increase in obese patients ${ }^{22}$. Additionally, epicardial adipose tissue was also found to be positively correlated with serum CysC, leptin, body mass index, and age. On the other hand, when CysC was replaced with eGFR, eGFR showed no significant correlation with epicardial adipose tissue ${ }^{23}$. Others have found circulating CysC to be consistently elevated in obese subjects, independently of reduced eGFR. This finding may be supported by $\mathrm{Cys} C$ role on regulatory mechanisms engaged to control the pro-atherogenic activity of specific cathepsins ${ }^{24}$. Taken together, these reports favor the pathogenic role of $\mathrm{Cys} C$ in atherogenesis.

In our study, CysC levels were found to be elevated in older patients, patients with past or present history of smoking, ischemic heart disease, and cerebrovascular disease, though without statistical significance. We also found CysC levels to be correlated with body fat composition, with higher levels of CysC identified in subjects with higher relative fat percentage, and inversely correlated with relative LTM. Conversely, CysC negative correlation with nPCR supports that higher $\mathrm{CysC}$ levels correlated with worse nutritional status, however statistical significance was lost once adjustment for RRF was applied. As others have suggested, lower nPCR was associated with poorer nutritional status and increased risk of all-cause mortality in PD patients ${ }^{25}$.

A recent study in PD patients reported that in obese patients, fat tissue index and leptin/adiponectin ratio were correlated with HOMA-IR, independently of glucose absorption, small-solute transport, and time on $\mathrm{PD}^{26}$. In our study, we failed to show any statistically significant association of $\mathrm{CysC}$ with leptin, insulin resistance score, and glycated hemoglobin. Additionally, we did not find $\mathrm{CysC}$ to be associated with inflammatory parameters such as ferritin or c-reactive protein.

In the multivariate model, relative fat body composition was associated with a protective effect of CVD. Indeed, overall higher relative fat percentage could reflect less severe systemic disease and improved nutritious status. However, we did not assess body fat distribution, so whether this relative fat percentage was referring to visceral or subcutaneous fat could not be determined. 
A previous study in both $\mathrm{PD}$ and hemodialysis patients with minimal RRF found $\mathrm{CysC}$ to be associated with adverse cardiovascular and infection events independently of the GFR ${ }^{14}$. Nevertheless, our results did not support a statistically significant association of $\mathrm{Cys} C$ with cardiovascular disease, independently of RRF.

We acknowledge the limitations of our study, namely its observational and cross-sectional design, so causality cannot be established. Furthermore, we enrolled a relatively small cohort of PD patients, limiting the generalization of our results.

However, it must be emphasized that our study found $\mathrm{CysC}$ to be increased in patients with lower renal weekly creatinine clearance, supporting its wellknown association with GFR.

To summarize, $\mathrm{Cys} C$ is a candidate biomarker of RRF in dialysis patients but potential confounders must be excluded in order to support its accuracy. Our study did not find a significant association of $\mathrm{CysC}$ levels with the metabolic profile and CVD events, but did suggest a tight correlation with RRF.

\section{AUTHOR"S CONTRIBUTION}

Carla Leal Moreira, Liliana Cunha, Sofia Correia, Filipa Silva, Ana Castro, Joana Tavares, Maria João Carvalho, José Carlos Oliveira, Olívia Santos, António Cabrita and Anabela Rodrigues contributed substantially to the conception or design of the study; collection, analysis, or interpretation of data; writing or critical review of the manuscript; and final approval of the version to be published.

\section{Conflict of InTEREST}

We have read and understood Nephrology policy on disclosing conflicts of interest and declare that we have none.

\section{References}

1. Mathisen UD, Melsom T, Ingebretsen OC, Jenssen T, Njoldstad I, Solbu MD, et al. Estimated GFR associates with cardiovascular risk factors independently of measured GFR. J Am Soc Nephrol. 2011 May;22(5):927-937.

2. Wu CK, Lin JW, Caffrey JL, Chang MH, Hwang JJ, Lin YS. Cystatin $\mathrm{C}$ and long-term mortality among subjects with normal creatinine-based estimated glomerular filtration rates: NHANES III (Third National Health and Nutrition Examination Survey). J Am Coll Cardiol. 2010 Nov;56(23):1930-6.

3. Schöttker B, Herder C, Müller H, Brenner H, Rothenbacher D. Clinical utility of creatinine-and cystatin C-based definition of renal function for risk prediction of primary cardiovascular events in patients with diabetes. Diabetes Care. 2012 Apr;35(4):879-86.
4. Laterza OF, Price CP, Scott MG. Cystatin C: an improved estimator of glomerular filtration rate? Clin Chem. 2002 May;48(5):699-707.

5. Stevens LA, Schmid CH, Greene T, Li L, Beck GJ, Joffe MM, et al. Factors other than glomerular filtration rate affect serum cystatin C levels. Kidney Int. 2009 Mar;75(6):652-60.

6. Grubb AO. Cystatin C - properties and use as diagnostic marker. Adv Clin Chem. 2000;35:63-99.

7. Kottgen A, Selvin E, Stevens LA, Levey AS, Van Lente F, Coresh J. Serum cystatin C in the United States: the Third National Health and Nutrition Examination Survey (NHANES III). Am J Kidney Dis. 2008 Mar;51(3):385-394.

8. Hoek FJ, Korevaar JC, Dekker FW, Boeschoten EW, Krediet RT. Estimation of residual glomerular filtration rate in dialysis patients from the plasma cystatin C level. Nephrol Dial Transplant. 2007 Jun;22(6):1633-8.

9. Yang Q, Li R, Zhong Z, Mao H, Fan J, Yang X, et al. Is cystatin $\mathrm{C}$ a better marker than creatinine for evaluating residual renal function in patients on continuous ambulatory peritoneal dialysis? Nephrol Dial Transplant. 2011 Oct;26(10):3358-65.

10. Shafi T, Michels WM, Levey AS, Inker LA, Dekker FW, Krediet $\mathrm{RT}$, et al. Estimating residual kidney function in dialysis patients without urine collection. Kidney Int. 2016 May;89(5):1099110.

11. Tangri N, Inker LA, Tighiouart H, Sorensen E, Menon V, Beck $\mathrm{G}$, et al. Filtration markers may have prognostic value independent of glomerular filtration rate. J Am Soc Nephrol. 2012 Feb;23(2):351-9.

12. Foster MC, Inker LA, Levey AS, Selvin E, Eckfeldt J, Juraschek SP, et al. Novel filtration markers as predictors of all-cause and cardiovascular mortality in US adults. Am J Kidney Dis. 2013 Jul;62(1):42-51.

13. Foster MC, Weiner DE, Bostom AG, Carpenter MA, Inker LA, Jarolim P, et al. Filtration markers, cardiovascular disease, mortality, and kidney outcomes in stable kidney transplant recipients: the FAVORIT trial. Am J Transplant. 2017 Sep;17(9):2390-9.

14. Ho LC, Sung JM, Tsai YS, Wang HH, Li YC, Chen YT, et al. Cystatin $\mathrm{C}$ as a predictor for outcomes in patients with negligible renal function. Blood Purif. 2014;38(2):81-8.

15. Moissl UM, Wabel P, Chamney PW, Bosaeus I, Levin NW, Bosy-Westphal A, et al. Body fluid volume determination via body composition spectroscopy in health and disease. Physiol Meas. 2006 Sep;27(9):921-33.

16. Wabel P, Chamney P, Moissl U, Jirka T. Reproducibility of bioimpedance spectroscopy (BIS) in health and disease. Nephrol Dial Transpl. 2007;22(Suppl 6):137.

17. Moissl U, Wabel P, Chamney PW. Validation of a bioimpedance spectroscopy method for the assessment of fat free mass. NDT Plus. 2008 Jan;1(Suppl 2):215.

18. Chamney PW, Krämer M, Rode C, Kleinekofort W, Wizemann V. A new technique for establishing dry weight in hemodialysis patients via whole body bioimpedance. Kidney Int. 2002 Jun;61(6):2250-8

19. Nolph KD, Moore HL, Twardowski ZJ, Khanna R, Prowant $\mathrm{B}$, Meyer M, et al. Cross-sectional assessment of weekly urea and creatinine clearances in patients on continuous ambulatory peritoneal dialysis. ASAIO J. 1992 Jul/Sep;38(3):M139-42.

20. van Olden RW, Krediet RT, Struijk DG, Arisz L. Measurement of residual renal function in patients treated with continuous ambulatory peritoneal dialysis. J Am Soc Nephrol. 1996 May;7(5):745-50.

21. Johnson DW, Dent H, Hawley CM, McDonald SP, Rosman JB, Brown FG, et al. Association of dialysis modality and cardiovascular mortality in incident dialysis patients. Clin J Am Soc Nephrol. 2009 Oct;4(10):1620-8.

22. Naour N, Fellahi S, Renucci JF, Poitou C, Rouault C, Basdevant A, et al. Potential contribution of adipose tissue to elevated serum cystatin C in human obesity. Obesity (Silver Spring). 2009 Dec;17(12):2121-6. 
23. Murai T, Takebe N, Nagasawa K, Todate Y, Nakagawa R, Nakano R, et al. Association of epicardial adipose tissue with serum level of cystatin C in type 2 diabetes. PLoS One. 2017 Sep;12(9):e0184723.

24. Lafarge JC, Naour N, Clément K, Guerre-Millo M. Cathepsins and cystatin $\mathrm{C}$ in atherosclerosis and obesity. Biochimie. 2010 Nov;92(11):1580-6.
25. Fein PA, Weiss S, Avram MM, Ramos F, Singh P, See SY, et al. Relationship of normalized protein catabolic rate with nutrition status and long-term survival in peritoneal dialysis patients. Adv Perit Dial. 2015;31:45-8.

26. Bernardo AP, Oliveira JC, Santos O, Carvalho MJ, Cabrita A, Rodrigues A. Insulin resistance in nondiabetic peritoneal dialysis patients: associations with body composition, peritoneal transport, and peritoneal glucose absorption. Clin J Am Soc Nephrol. 2015 Dec 7;10(12):2205-12. 